\title{
CrimRxiv
}

\section{Victim Support and the Welfare State}

\section{Carina Gallo, Kerstin Svensson}

Published on: May 29, 2019

DOI: 10.21428/cb6ab371.71c0a046

License: Creative Commons Attribution 4.0 International License (CC-BY 4.0). 
